\title{
Does PRP enhance bone integration with grafts, graft substitutes, or implants? A systematic review
}

Alice Roffi ${ }^{1}$, Giuseppe Filardo ${ }^{1}$, Elizaveta Kon ${ }^{1 *}$ and Maurilio Marcacci ${ }^{2}$

\begin{abstract}
Background: Several bone implants are applied in clinical practice, but none meets the requirements of an ideal implant. Platelet-rich plasma (PRP) is an easy and inexpensive way to obtain growth factors in physiologic proportions that might favour the regenerative process. The aim of this review is to analyse clinical studies in order to investigate the role of PRP in favouring bone integration of graft, graft substitutes, or implants, and to identify the materials for which the additional use of PRP might be associated with superior osseo- and soft tissues integration.

Methods: A search on PubMed database was performed considering the literature from 2000 to 2012, using the following string: ("Bone Substitutes"[Mesh] OR "Bone Transplantation"[Mesh] OR "Bone Regeneration"[Mesh] OR "Osseointegration"[Mesh]) AND ("Blood Platelets"[Mesh] OR "Platelet-Rich Plasma"[Mesh]). After abstracts screening, the full-texts of selected papers were analyzed and the papers found from the reference lists were also considered. The search focused on clinical applications documented in studies in the English language: levels of evidence included in the literature analysis were I, II and III.

Results: Literature analysis showed 83 papers that fulfilled the inclusion criteria: 26 randomized controlled trials (RCT), 14 comparative studies, 29 case series, and 14 case reports. Several implant materials were identified: 24 papers on autologous bone, 6 on freeze-dried bone allograft (FDBA), 16 on bovine porous bone mineral (BPBM), 9 on $\beta$-tricalcium phosphate ( $\beta$-TCP), 4 on hydroxyapatite (HA), 2 on titanium (Ti), 1 on natural coral, 1 on collagen sponge, 1 on medicalgrade calcium sulphate hemihydrate (MGCSH), 1 on bioactive glass (BG) and 18 on a combination of biomaterials. Only 4 papers were related to the orthopaedic field, whereas the majority belonged to clinical applications in oral/maxillofacial surgery.
\end{abstract}

Conclusions: The systematic research showed a growing interest in this approach for bone implant integration, with an increasing number of studies published over time. However, knowledge on this topic is still preliminary, with the presence mainly of low quality studies. Many aspects still have to be understood, such as the biomaterials that can benefit most from PRP and the best protocol for PRP both for production and application.

Keywords: PRP, Implant integration, Platelets, Bone, Regenerative medicine

\section{Background}

Osseointegration is achieved when there is no progressive relative movement between the implant and the bone in direct contact with it [1], and is the result of two complex stages: osteoinduction, the process by which osteogenesis is induced and osteoconduction, the growth of bone on a surface [2]. Osteoinduction is a part of the normal bone healing process and is responsible for the majority of

\footnotetext{
* Correspondence: e.kon@biomec.ior.it

${ }^{1}$ Nano-Biotechnology Laboratory, Rizzoli Orthopaedic Institute, Via di Barbiano n 1/10, Bologna 40136, Italy

Full list of author information is available at the end of the article
}

newly formed bone. Osteoconduction also occurs during normal remodelling in bone and depends not only on biological factors, but also on the response to a foreign material [2].

Several bone substitutes materials are currently being applied in clinical practice [3], but none meets all the requirements of an ideal implant. Ideally, to obtain good osseointegration, bone implants should provide four elements: structural integrity; an osteoconductive matrix as a scaffold that permits bone ingrowth; osteogenic cells, which offer the potential to differentiate and facilitate the various stages of bone regeneration; and osteoinductive
C Biomed Central 
factors, the mediators that induce the various stages of bone regeneration and repair [3].

Growth factors (GFs) are expressed during different phases of tissue healing and are therefore a key element in promoting tissue regeneration [4]; in fact, GFs carried on orthopaedic devices have been reported to enhance osteoblastic activity and favour implant integration $[5,6]$.

Platelet-rich plasma (PRP) is an inexpensive way to obtain many GFs in physiological proportion and has already been largely applied as a carrier of GFs in different fields of medicine (sports medicine, orthopaedics, dermatology, ophthalmology, plastic and maxillofacial surgery, neurosurgery, urology, and cardiothoracic surgery...) due to its property of favouring tissue healing even in tissues with low healing potential [7-10].

PRP can be defined as a blood derivate where platelets have a higher concentration above baseline levels. In clinical practice PRP has been applied in musculoskeletal treatment, with results reported on cartilage, bone, muscle, tendon and ligament regeneration, and also as an augmentation procedure to favour implant healing, although this aspect has not been largely documented in the literature $[7,9]$. The first evidence of the clinical benefits of PRP in implant osseointegration was reported in 1998 by Marx et al. [11], who studied 88 patients with mandibular defects treated with platelet concentrate and cancellous cellular marrow bone graft. Results showed that PRP allowed a radiographic graft maturation rate of 1.62 to 2.16 times higher than that without PRP at six months, and also showed greater bone density.
Since then the use of PRP has been broadened as an augmentation procedure for several applications.

The aim of this review is to analyse all the existing published clinical studies in order to investigate the role of PRP in favouring integration of bone-graft, bone-graft substitutes, or bone-implants with bone and/or soft tissues, and to identify the materials for which the additional use of PRP might be associated with superior osseo- and soft tissues integration.

\section{Methods}

A search was performed on the PubMed database considering the literature from 2000 to 2012, using the following string: ("Bone Substitutes"[Mesh] OR "Bone Transplantation"[Mesh] OR "Bone Regeneration"[Mesh] OR "Osseointegration"[Mesh]) AND ("Blood Platelets" [Mesh] OR "Platelet-Rich Plasma"[Mesh]). After abstracts screening, the full-texts of selected papers were analyzed and the papers found from the reference lists were also considered for the literature analysis of this review (Figure 1).

The search focused on clinical applications documented in studies in the English language: the levels of evidence for the literature analysis were I to III.

Papers were classified according to the level of evidence and biomaterial in order to understand the potential of PRP to favour the osseointegration of different types of biomaterials. In particular, RCTs have been analysed in the text and summarized in Table 1, whereas comparative trials were synthesize in Table 2. Only

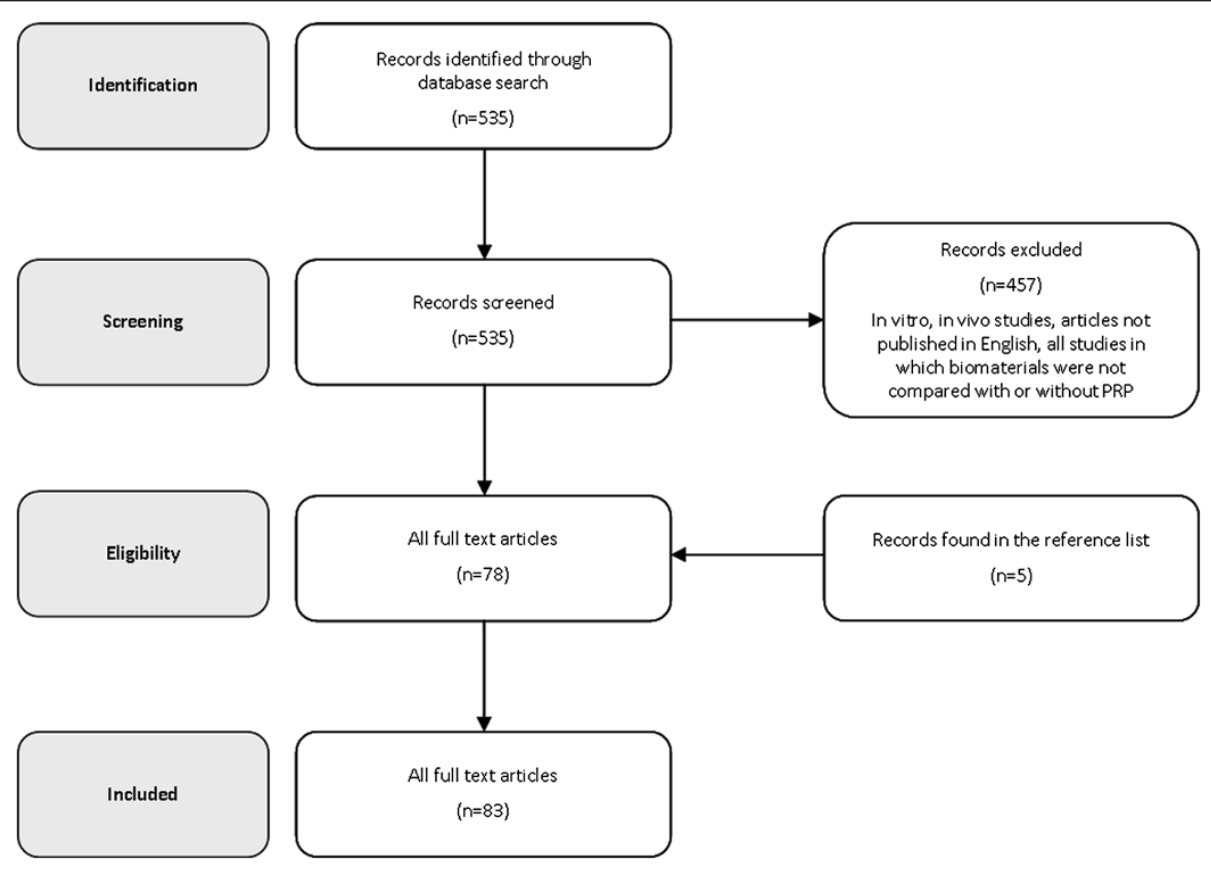

Figure 1 Flow diagram of the systematic review process. 
Table 1 Published results on PRP clinical application to favor bone implant integration (R: randomized trial; C: comparative study; +: results in favor of PRP; -: no benefit from PRP; +/-: doubtful results on PRP usefullness for bone scaffold integration)

\begin{tabular}{|c|c|c|c|c|c|c|c|c|c|}
\hline & Publication & $\mathrm{N}^{\circ}$ pts & $\begin{array}{l}\text { Study } \\
\text { type }\end{array}$ & Results & & Publication & $\mathrm{N}^{\circ}$ pts & $\begin{array}{l}\text { Study } \\
\text { type }\end{array}$ & Results \\
\hline \multirow{20}{*}{$\begin{array}{l}\text { Autologous } \\
\text { bone }\end{array}$} & Khairy NM [12] & 15 & $\mathrm{R}$ & + & BPBM & Camargo PM [13] & 28 & C & $+/-$ \\
\hline & J Oral Maxillofac Surg - 2012 & & & & & Int J Per Rest Dent - 2005 & & & \\
\hline & Wei LC [14] & 276 & $\mathrm{R}$ & + & & Hanna R [15] & 13 & $\mathrm{R}$ & $+/-$ \\
\hline & J Orthop Res - 2012 & & & & & J Periodontol - 2004 & & & \\
\hline & Sys J [16] & 40 & $\mathrm{R}$ & - & & Lekovic V [17] & 52 & C & $+/-$ \\
\hline & Eur Spine J - 2011 & & & & & J Clin Periodontol - 2003 & & & \\
\hline & Luaces-Rey R [18] & 20 & C & - & & Camargo PM [19] & 18 & C & $+/-$ \\
\hline & $\begin{array}{l}\text { Med Oral Patol Oral } \\
\text { Cir Bucal - } 2010\end{array}$ & & & & & J Periodontal Res - 2002 & & & \\
\hline & Badr M [20] & 21 & $\mathrm{R}$ & - & $\beta-\mathrm{TCP}$ & Ozdemir B [21] & 14 & $\mathrm{R}$ & - \\
\hline & Eur J Oral Implantol - 2010 & & & & & J Biomed Mater Res B - 2012 & & & \\
\hline & Bettega G [22] & 18 & C & + & & Saini N [23] & 20 & C & + \\
\hline & Transfusion - 2009 & & & & & Indian J Dent Res - 2011 & & & \\
\hline & Lee C [24] & 30 & C & + & & Harnack L [25] & 22 & $\mathrm{R}$ & - \\
\hline & Int J Oral Maxillofac Surg - 2009 & & & & & Clin Oral Investig - 2009 & & & \\
\hline & Schaaf H [26] & 34 & R & - & & Dori F [27] & 28 & $\mathrm{R}$ & - \\
\hline & Oral Surg Radiol Endod - 2008 & & & & & J Periodontol - 2008 & & & \\
\hline & Consolo U [28] & 16 & $\mathrm{R}$ & + & & Yassibag-Berkman Z [29] & 25 & $\mathrm{R}$ & - \\
\hline & Clin Oral Impl Res - 2006 & & & & & J Periodontol - 2007 & & & \\
\hline & Raghoebar GM [30] & 30 & $\mathrm{R}$ & - & & Wiltfang J [31] & 39 & $\mathrm{R}$ & + \\
\hline & Clin Oral Implants Res - 2005 & & & & & Clin Oral Implants Res - 2003 & & & \\
\hline \multirow[t]{6}{*}{ FDBA } & Markou N [32] & 24 & R & - & HA & Menzes LM [33] & 60 & $\mathrm{R}$ & + \\
\hline & J Periodontol - 2009 & & & & & Quitessence Int - 2012 & & & \\
\hline & Piemontese M [34] & 60 & $\mathrm{R}$ & - & & Vaishnavi C [35] & 20 & $\mathrm{R}$ & + \\
\hline & J Periodontol - 2008 & & & & & J Conserv Dent - 2011 & & & \\
\hline & Kassolis JD [36] & 10 & $\mathrm{R}$ & + & & Okuda K [37] & 35 & $\mathrm{R}$ & $+/-$ \\
\hline & J Craniofac Surg - 2005 & & & & & J Periodontol - 2005 & & & \\
\hline \multirow[t]{14}{*}{ BPBM } & Anitua E [38] & 5 & C & + & BG & Demir B [39] & 29 & $\mathrm{R}$ & - \\
\hline & Clin Impl Dent Rel Res - 2012 & & & & & J Clin Periodontol - 2007 & & & \\
\hline & Cabbar F [40] & 10 & C & - & $\mathrm{Ti}$ & Monov G [41] & 10 & C & - \\
\hline & J Oral Maxillofac Surg - 2011 & & & & & Clin Oral Implants Res - 2005 & & & \\
\hline & Yilmaz S [42] & 20 & C & - & MGCSH & Kutkut A [43] & 16 & $\mathrm{R}$ & $+/-$ \\
\hline & J Periodontol - 2011 & & & & & J Periodontol - 2012 & & & \\
\hline & Camargo PM [44] & 23 & C & - & Biomaterials & Poeschl PW [45] & 14 & C & + \\
\hline & J Periodontol - 2009 & & & & & J Oral Maxillofac Surg - 2012 & & & \\
\hline & Torres J [46] & 87 & $\mathrm{R}$ & + & & Inchingolo F [47] & 127 & C & + \\
\hline & J Clin Periodontol - 2009 & & & & & Eur Rev Med Pharmacol Sci - 2012 & & & \\
\hline & Dori F [48] & 24 & $\mathrm{R}$ & - & & Kaushick BT [49] & 10 & $\mathrm{R}$ & + \\
\hline & J Periodontol - 2007 & & & & & Indian J Dent Res - 2011 & & & \\
\hline & Dori F [50] & 30 & R & - & & Torres J [51] & 30 & $\mathrm{R}$ & + \\
\hline & J Clin Periodontol - 2007 & & & & & J Clin Periodontol - 2010 & & & \\
\hline
\end{tabular}


Table 2 Comparative studies on PRP clinical application to favor bone-graft, bone-graft substitutes, or bone implant integration

\begin{tabular}{|c|c|c|c|c|c|}
\hline & Publication & Results & & Publication & Results \\
\hline \multirow[t]{3}{*}{$\begin{array}{l}\text { Autologous } \\
\text { bone }\end{array}$} & $\begin{array}{l}\text { Luaces-Rey R [18] Med Oral } \\
\text { Patol Oral Cir Bucal - } 2010\end{array}$ & $\begin{array}{c}\text { Bone increase between the third and sixth months, in } \\
\text { autologous bone alone or in combination with PRP } \\
\text { without any statistical difference }\end{array}$ & BPBM & $\begin{array}{l}\text { Camargo PM [13] Int J } \\
\text { Per Rest Dent - } 2005\end{array}$ & $\begin{array}{c}\text { Decrease in pocket depth and an increase in clinical } \\
\text { attachment level and defect filling, with BPBM, GTR, } \\
\text { and PRP in comparison to open flap } \\
\text { debridement group }\end{array}$ \\
\hline & $\begin{array}{l}\text { Bettega G [22] } \\
\text { Transfusion - } 2009\end{array}$ & $\begin{array}{c}\text { PRP permitted a } 60 \% \text { reduction in the amount of } \\
\text { bone graft required for normal sinus floor augmentation } \\
\text { and the bone obtained had the same histological } \\
\text { and mechanical properties as the bone obtained } \\
\text { by traditional graft }\end{array}$ & & $\begin{array}{l}\text { Lekovic V [17] J Clin } \\
\text { Periodontol - } 2003\end{array}$ & $\begin{array}{c}\text { Greater pocket reduction, an increase in clinical } \\
\text { attachment level, vertical and horizontal defect } \\
\text { filling in the BPBM/GTR/PRP group respect to } \\
\text { open flap debridement }\end{array}$ \\
\hline & $\begin{array}{l}\text { Lee C [24] Int J Oral } \\
\text { Maxillofac Surg - } 2009\end{array}$ & $\begin{array}{l}\text { PRP acceleration of early bone remodelling, but no } \\
\text { significant differences in bone resorption rate between } \\
\text { PRP and particulate cancellous bone and marrow } \\
\text { (PCBM) vs PCBM alone }\end{array}$ & & $\begin{array}{l}\text { Camargo PM [19] J } \\
\text { Periodontal Res - } 2002\end{array}$ & $\begin{array}{l}\text { High pocket depth reduction, clinical attachment } \\
\text { gain and defect filling in the PRP/BPBM group }\end{array}$ \\
\hline \multirow[t]{4}{*}{ BPBM } & $\begin{array}{l}\text { Anitua E [38] Clin Impl } \\
\text { Dent Rel Res - } 2012\end{array}$ & $\begin{array}{l}\text { More new vital bone than that of the controls in } \\
\text { PRGF-treated samples, and well incorporated bovine } \\
\text { into the new bone formation in the PRGF group }\end{array}$ & $\beta$-TCP & $\begin{array}{l}\text { Saini N [23] Indian J } \\
\text { Dent Res - } 2011\end{array}$ & $\begin{array}{l}\text { Clinical and radiographic improvement } \\
\text { when PRP was added to } \beta \text {-TCP }\end{array}$ \\
\hline & $\begin{array}{l}\text { Cabbar F [40] J Oral } \\
\text { Maxillofac Surg - } 2011\end{array}$ & $\begin{array}{l}\text { No significant differences in BPBM plus PRP or } \\
\text { alone: bone integration and residual graft particles in } \\
\text { all patients at histological analysis }\end{array}$ & $\mathrm{Ti}$ & $\begin{array}{l}\text { Monov G [52] Clin Oral } \\
\text { Implants Res - } 2005\end{array}$ & $\begin{array}{l}\text { No statistically significant differences between } \\
\text { titanium plus PRP or titanium alone group }\end{array}$ \\
\hline & $\begin{array}{l}\text { Yilmaz S [42] } \\
\text { J Periodontol - } 2011\end{array}$ & $\begin{array}{l}\text { At } 12 \text { months, similar results in probing depth } \\
\text { reduction, attachment gain, clinical and radiographic } \\
\text { bone gain between BPBM plus PPP or plus PRP groups }\end{array}$ & $\begin{array}{l}\text { Biomaterials } \\
\text { combination }\end{array}$ & $\begin{array}{l}\text { Poeschl PW [53] J Oral } \\
\text { Maxillofac Surg - } 2012\end{array}$ & $\begin{array}{l}\text { Significantly better overall graft resorption and } \\
\text { increase in bone formation occurred when PRP } \\
\text { was added to algae-derived HA, Cgraft and } \\
\text { Algipore respect to biomaterials alone }\end{array}$ \\
\hline & $\begin{array}{l}\text { Camargo PM [44] J } \\
\text { Periodontol - } 2009\end{array}$ & $\begin{array}{c}\text { Similar results between BPBM/GTR alone or in } \\
\text { combination with PRP in the decrease of probing } \\
\text { depth, gain in clinical attachment and bone filling } \\
\text { of the defect. }\end{array}$ & & $\begin{array}{l}\text { Inchingolo F [54] Eur Rev } \\
\text { Med Pharmacol Sci - } 2012\end{array}$ & $\begin{array}{l}\text { At radiographic point of view presence of newly } \\
\text { formed bone tissue, well amalgamated with the } \\
\text { residual bone in PRP plus autologous bone, } \\
\text { anorganic bone material (Bio-Oss, HA) and organic } \\
\text { bone substitutes vs autologous bone alone }\end{array}$ \\
\hline
\end{tabular}


papers that compared the results of specific treatments with or without PRP were considered. Those using PRP in all the treated groups and where other factors were the only difference were excluded. All papers documenting PRP augmentation for orthopaedic procedures were described separately to understand the evidence available on its potential in this field.

\section{Results}

The literature analysis showed 83 papers on this topic: 26 randomized controlled trials (RCT), 14 comparative studies, 29 case series, and 14 case reports. The results showed an increasing interest in this topic over time. According to the type of material, several implant types were identified: 24 papers on autologous bone use, 6 on freeze-dried bone allograft (FDBA), 16 on bovine porous bone mineral (BPBM), 9 on $\beta$-tricalcium phosphate ( $\beta$-TCP), 4 on hydroxyapatite (HA), 2 on titanium (Ti), 1 on natural coral, 1 on collagen sponge, 1 on medicalgrade calcium sulphate hemihydrate (MGCSH), 1 on bioactive glass (BG), and 18 on a combination of biomaterials. Only 4 papers were related to the orthopaedic field, whereas the majority of the results belonged to clinical applications in oral/maxillofacial surgery.

\section{Autologous bone}

Autologous bone represents the gold standard for bone replacement, because it offers minimal immunological rejection, complete histocompatibility, provides the best osteoconductive and osteoinductive properties, and is inexpensive and easy to obtain [55]. Nevertheless, it also has some drawbacks, such as donor site morbidity, need for general anesthesia or sedation, occasional need for more than one surgical site and limited availability [55]. Several studies have reported its use in combination with PRP to improve bone implant integration.

In 2005 Raghoebar et al. [30] analysed 30 patients that underwent floor augmentation of the maxillary sinus and were randomly assigned to autologous bone graft and PRP or autologous bone alone. No differences between treatments were observed, thus showing no additional value of PRP on implant integration. Conversely, in 2006 Consolo et al. [28] reported the regenerative potential of PRP when used with autologous bone, but this effect appeared to be restricted to shorter treatment times: 16 patients underwent bilateral sinus floor augmentation, using autologous bone on one side and PRP plus autologous bone contralaterally. At 4 months, the PRP group showed higher bone activities documented by histological analysis, but a progressive extinguishment of the PRP effect was recorded after a time of longer than 6-7 months. In 2008 Schaaf et al. [26] showed no significant differences in bone volume and implant failure using autologous bone graft alone or in combination with PRP in 34 sinus floor augmentations. In 2010, Badr et al. [20] used PRP in combination with bone iliac crest graft in maxilla defects: 22 patients were randomly divided into two groups: PRP augmented and controls. No significant differences were detected for implant stability or mean graft resorption and soft tissue healing indices. Only the posterior implant subgroup showed higher stability values, although not clinically significant. Finally in 2012, Khairy et al. [12] evaluated the potential benefit of PRP in conjunction with autologous bone for maxillary sinus augmentation in 15 patients; autogenous bone alone was used as the control group. PRP improved the handling properties of the graft material but did not improve bone density at 3 months. However, PRP-enriched bone grafts were associated with superior bone density at 6 months.

\section{Freeze-dried bone allograft}

FDBA is derived from the removal of water by the frozen tissue with subsequent vacuum-packing and storing at room temperature for up to 5 years [3].

Kassolis et al. [36] in 2005 investigated the use of PRP in combination with FDBA in 10 patients who underwent bilateral maxillary subantral sinus augmentation. The subjects were randomly assigned to FDBA plus PRP or FDBA plus resorbable membrane of polytetrafluoroethylene (e-PTFE). Biopsies were obtained 4.5 to 6 months after treatment and revealed a significantly higher percentage of sinus vital tissue in the PRP group. A lower percentage of residual graft particles and a higher rate of bone formation, although not significant, were detected in the PRP treatment group. In 2008, Piemontese et al. [34] performed a double-blinded RCT on 60 patients with infrabony osseous defects derived from chronic periodontitis and treated with FDBA and PRP or FDBA alone. One year after treatment, both groups showed similar significant changes in the gingival index, bleeding on probing, probing depth, clinical attachment level and radiographic parameters, but a greater probing depth reduction and clinical attachment gain were seen in the PRP group. However, with regards to bone regeneration, PRP did not seem to give any additional value. Similarly, in 2009 Markou et al. [32] compared FDBA plus PRP with FDBA alone in 24 patients with severe chronic periodontitis. At six months the two treatment groups were comparable and the percentage of defect filling did not differ significantly.

\section{Bovine porous bone mineral}

BPBM is a xenograft prepared by protein extraction of bovine bone, which results in a structure similar to human cancellous bone and has the ability to enhance bone formation [56]. The advantages of xenografts include their relative abundant supply, ease of use, and 
potentially favourable clinical performance. Although rare, one drawback in its use concerns the possible risk of disease transmission, such as bacterial, viral, and prion transmission [57].

The combination of PRP and BPBM has been applied by many research groups, mainly focusing on periodontal regenerative therapy.

In 2004, Hanna et al. [15] reported their experience in the treatment of periodontal intrabony defects using BPBM and PRP: 13 patients were randomly assigned to $\mathrm{BPBM}$ or BPBM plus PRP groups. After 6 months significant benefits with both treatments were revealed, but in the PRP group better results were found in probing reduction and clinical attachment level. In 2007, Dori et al. [48] investigated the use of BPBM/GTR alone or in combination with PRP for the treatment of 24 intrabony defects related to chronic periodontal disease, and showed no differences in any of the studied parameters. Similar results were reported in another RCT performed by the same author, who in 2007 analysed 30 patients treated with BPBM/GTR/PRP or BPBM/GTR alone: PRP did not give any additional value [50]. Conversely, a good clinical outcome was reported by Torres et al. [46] two years later: 87 patients underwent sinus floor augmentation with BPBM alone or in combination with PRP. Histological analysis revealed that bone regeneration was significantly higher in sites treated with PRP and BPBM, whereas graft resorption was similar in both groups.

\section{Ceramics}

Ceramics have been widely used for their osteoconductive properties. Most calcium phosphate ceramics currently under investigation are synthetic and composed of HA $\left(\mathrm{Ca}_{10}\left[\mathrm{PO}_{4}\right]_{6}\left[\mathrm{OH}_{2}\right]\right)$, TCP $\left(\mathrm{Ca}_{3}\left[\mathrm{PO}_{4}\right]_{2}\right)$, or a combination of the two [3]. Clinically good short-term results have been reported for bone grafting with ceramic bone substitute materials [58].

\section{$\beta$-Tricalcium phosphate}

In 2003, Wiltfang et al. [31] analysed 39 patients undergoing sinus floor elevation with $\beta$-TCP alone or in combination with PRP. At 6 months, the formation of new bone was $8-10 \%$ higher when PRP was added, even if it did not accelerate the degradation of the ceramic bone substitute. Four years later, Yassibag-Berkman et al. [29] tested the efficacy of $\beta$-TCP alone or in combination with PRP and GTR in 25 patients: the defects were randomly and equally assigned to three groups, $\beta$-TCP alone, $\beta$-TCP with PRP and $\beta$-TCP with PRP and GTR. No statistically significant differences in clinical and radiographic measurements were observed among the groups.
In 2008, Dori et al. [27] investigated the use of PRP and $\beta$-TCP in subjects with intrabony defects caused by chronic periodontal disease: 28 patients were randomly divided into two groups, PRP plus $\beta$-TCP and GTR vs $\beta$ TCP plus GTR. No significant differences between the groups were observed, thus no additional value was provided by PRP. One year later, Harnack et al. [25] reported the results of an RCT including 22 patients with intrabony defect caused by periodontitis treated with $\beta$ TCP in combination with PRP or alone. Both groups showed a similar clinical improvement, thus suggesting that PRP did not enhance or improve bone healing or $\beta$ TCP integration. More recently, Ozdemir et al. [21] treated 14 patients with chronic periodontitis (a total of 28 defects) using PRP plus $\beta$-TCP or $\beta$-TCP alone: no statistically significant differences between the two groups in clinical and radiographic values were observed.

\section{Hydroxyapatite}

In 2005, Okuda et al. [37] reported promising results using HA together with PRP: 35 patients were treated with HA alone or in combination with PRP and they were evaluated at one year. Significant changes in probing reduction, clinical attachment gain and vertical relative attachment gain suggested that PRP may led to more favourable results compared to HA alone.

More recently in 2011, Vaishnavi et al. [35] showed good results evaluating 20 subjects randomly assigned to four treatments: HA, PRP, HA plus PRP, and no substitutes. Radiographic evaluation showed complete bone regeneration in group I at 1 year, group II at the end of 9 months, group III at the end of 6 months, whereas the last group showed no satisfactory bone regeneration, even at the end of one year. This suggests that PRP favours better and faster bone regeneration combined with HA. Finally, in 2012 Menezes et al. [33] treated 60 intraosseous defects derived from chronic periodontitis with PRP and HA or a mixture of HA and saline. The 1-year results showed no significant changes when compared with baseline; however, the 4-year results indicated that the test group exhibited a more favourable clinical improvement in intraosseous periodontal defects.

\section{Bioactive glass}

Among various subgroups of alloplastic bone grafts, BG is a kind of bioactive ceramic [59] consisting of $\mathrm{SiO} 2$, $\mathrm{CaO}, \mathrm{Na} 2 \mathrm{O}$ and $\mathrm{P} 2 \mathrm{O} 5$. It has been suggested that bioactive glasses bond to bone without a fibrous connective tissue interface [60]. Schepers and Ducheyne [60] evaluated bone growth around bioactive glass particles in dog bone defects in comparison to hydroxylapatite particles, and reported that narrow-size $(300-355 \mathrm{~mm})$ BG has an osteostimulatory effect besides its osteoconductive properties. Moreover, in soft and hard tissue measurements 
no significant differences were reported between demineralized freeze-dried bone allografts (DFDBA) and BG grafted sites [61]. In 2007, Demir et al. [39] randomly treated 29 intra-bony defects with either PRP/BG or BG alone, and found no additional benefit in the reduction of pocket depth, clinical attachment gain, and defect filling.

\section{MGCSH}

MGCSH is a material that has a long history of clinical use, thanks to its biocompatibility and rapid and complete resorption, although these properties can sometimes be a drawback in the healing process. MGCSH can be used as a carrier to deliver GFs. In 2012, Kutkut et al. [62] reported promising results with PRP and MGCSH: after extraction of a tooth 16 patients received a combination of MGCSH/PRP (test group) or collagen resorbable plug dressing material (control group). The rate of new vital bone after 3 months of healing was $66.5 \%$ in the test group compared to $38.3 \%$ in the control group. Moreover, PRP enhanced rapid bone healing with respect to PRP-free collagen resorbable graft, but the difference in the material used in the study group prevents a true assessment of the role of PRP.

\section{Biomaterial combinations}

Biomaterials can also be used in combination to incorporate all the favourable material properties in one implant.

In 2010, Torres et al. [63] investigated the role of PRP in alveolar ridge augmentation with Ti-mesh and BPBM. Higher bone augmentation and no Ti-mesh exposure were seen in the PRP group. One year later, Kaushick et al. [41] investigated the use of PRP together with HA/ b-TCP: defects of 10 patients were randomly assigned to test (PRP/HA/b-TCP) or saline-HA/b-TCP. PRP permitted a greater reduction in probing pocket depth, gain in attachment level and amount of radio density with respect to the control group.

The present analysis suggests that PRP might not be indicated for b-TCP implants, controversial results are obtained with autologous bone, whereas a better potential seems to lie in the augmentation of HA implants. In particular, only 2 out of 6 papers showed good results for the integration of $\beta$-TCP, 5 out of 10 for autologous bone, 1 out of 3 for FDBA, 2 out of 11 for BPBM (4 with less clear evidence of PRP effect), whereas 2 out of 3 papers showed good results for the integration of HA (the third one showed some benefit but with less clear evidence).

\section{Orthopaedic papers}

Only a few orthopaedic papers were found in the present search. In 2007, Smrke et al. [43] described the use of allogenic PRP in combination with autologous cancellous bone for the treatment of a tibial fracture and delayed union after insufficient initial osteosynthesis in a 50-yearold type 2 diabetic man. After 6 months, the graft was incorporated, the bone defect was fully bridged and full weight-bearing capacity was achieved. No side effects and no signs of platelet or HLA I antibodies were reported. In the same year, Dallari et al. [51] also showed good results in 33 patients undergoing high tibial osteotomy to treat genu varum. Subjects treated with lyophilized bone chips and PRP, with or without bone marrow stromal cells showed better osseointegration and faster bone healing. In 2011 Sys et al. [49] assessed both the clinical and radiological effect of PRP with autogenous bone in posterior lumbar interbody fusion. Forty patients were randomly treated with autogenous bone alone or in combination with PRP; the subjects were examined at $3,6,12$, and 24 months postoperatively. The radiographic outcome showed uneventful osseous healing in all patients with no significant differences, but clinical improvement was more pronounced (even if not significantly) in patients who received autografts with PRP. More recently, Wei et al. [45] investigated the use of the same construct to treat $276 \mathrm{cal}-$ caneal fractures: the subjects were randomly divided into 3 groups: autogenous bone alone; allograft bone with PRP; and allograft alone. Results showed that PRP augmented the favourable outcome of allografts in the management of displaced calcaneal fractures: at 12 months no significant differences were found between 3 groups, but at 24 and 72 months the results of autologous bone and the allograft with PRP were similar and both were significantly better than the allograft alone.

\section{Discussion}

This systematic research has shown a growing interest in this biological treatment approach as augmentation procedure to favour integration of bone-graft, bone-graft substitutes, or bone implants with bone and soft tissues, by documenting an increasing number of published studies over time. However, knowledge on this topic is still preliminary, as demonstrated by the presence of low quality studies due to weak methodology, small number of patients and short-term follow-up.

The orthopaedic and oral/maxillofacial implants sector forms a significant portion of the biomedical industry and represents a combined $\$ 2.8$ billion market [47]. The clinical need in all of these areas is justified by increasing prevalence of physically active lifestyles and higher expectations of quality of life in older age groups as well as the ageing population affected by problems of bone healing. Success in the application of an implant depends on many and interconnected factors, that Wang et al. identified as surgeon, patient, and implant factors [6]. However, implant failure may be prevented by adding many coadjuvant agents, which may enhance implant 
osseointegration potential and restore bone tissue function. Among these, PRP is emerging as a powerful tool for soft and hard tissue healing, thanks to the GFs contained in platelet alpha-granules.

The search showed that among RCT and comparative papers, 16 reported favourable results for PRP augmentation, 18 obtained no significant difference with or without PRP and 6 underlined the doubtful role of PRP.

The great heterogeneity of clinical outcomes can be also explained by the different PRP products that have been used: several different procedures have been described to obtain PRP, thus implying qualitative and quantitative differences among substances (number of platelets concentrated, leukocyte content,..) [64]. Weibrich et al. [65] showed in vivo that PRP seems to be able to activate the osseous regeneration processes under optimized conditions, but these are not completely understood and require further studies. PRP activation is another source of variability: some authors do not activate platelets, whereas others use autologous thrombin, calcium chloride, and even physical methods or biomaterials [7]. Finally, applicative protocols can vary widely in terms of amount of substance, number of administrations and timing.

Another controversial point that adds a new variable to this specific type of application concerns the identification of a material that seems to benefit best from PRP augmentation: the lack of comparison between healing potential of biomaterials and PRP, differences in study design and in defects sizes, and low number of patients studied are the main problems that hamper the drawing of conclusions.

The present analysis of RCT and comparative studies showed that a combination of autogenous bone and PRP led to good results only in 5/10 trials, and only 1 of 3 and 2 of 11 studies reported a good clinical outcome using FDBA and BPBM, respectively. A clinical comparative trial published in 2008 and performed by Czuryszkiewicz-Cyrana [16] described a better clinical outcome when PRP was added to autologous bone compared to the addition to $\beta-\mathrm{TCP}$, thus confirming the present literature findings: only 2 of $6 \mathrm{~b}$-TCP trials found a positive role of PRP during osseointegration. HA implants seem to be the ideal candidate since good clinical outcomes were achieved in all the papers described and promising results, but less conclusive findings, have been reported with combinations of biomaterials. Finally, only one paper was found for both BG and MGCSH with contrasting results: PRP does not add any value when used in combination with BG, whereas it seems to provide positive and faster results with MGCSH.

Summarizing, for most of the documented applications we do not have enough evidence to draw clear conclusions on the role of PRP as an augmentation procedure. Fortunately, the number of high quality studies are increasing over time, compared to case series and case reports, as shown in Figure 2, and hopefully in the near future some of the many still open questions might be answered. The present analysis suggests that PRP might not be indicated for b-TCP implants, controversial results are obtained with autologous bone, whereas a better potential seems to lie in the augmentation of HA implants. One aspect to be considered is that, besides having a good effect or lack of effect, it does not seem that PRP had a negative effect. However, the weakness of the literature in this field and preclinical findings of a potentially deleterious effect [14] suggest caution and applying PRP as an augmentation procedure only in controlled studies until more evidence will give us better indications on the safety and potential of this biological treatment approach.

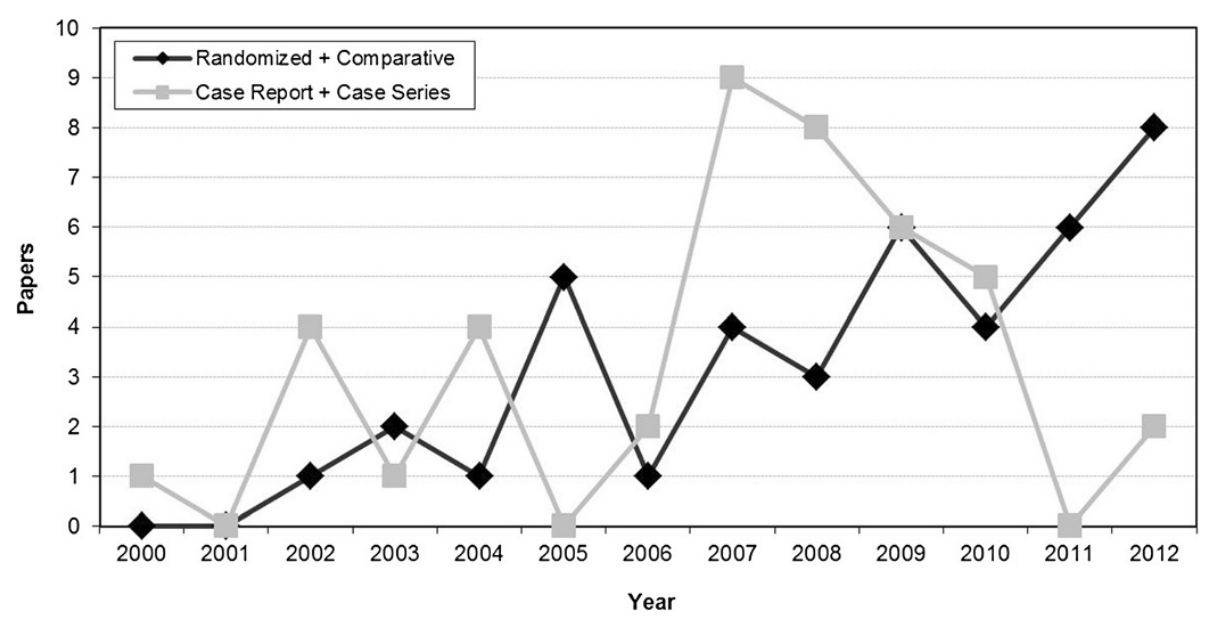

Figure 2 The literature analysis shows a growing interest on this PRP application. In particular an increasing number of high-quality trials is highlighted. 
An emerging aspect that could represent a further possible application modality of this biological treatment is the potential use of PRP in combination with other bioactive molecules involved in bone metabolism cascade, as bone morphogenetic proteins (BMPs) [66]. It is well known that these molecules can induce bone formation in a variety of indications [67], and recent findings showed that PRP combined with human recombinant BMP2 may promote bone formation in bony defects [67]. This seems to be a promising development of PRP use as augmentation procedure and might provide a fascinating approach to explore in the near future for the enhancement of osteointegration. However, as for all the various applications analysed in this systematic review, the real potential of this blood derivative still needs to be studied and robust trials are required before an indiscriminate application of PRP in the clinical practice.

\section{Conclusions}

Systematic research showed a growing interest in this treatment approach for the integration of bone-graft, bone-graft substitutes, or bone implants, with an increasing number of published studies over time. However, knowledge on this topic is still preliminary, and the few studies available are mainly of low quality.

We do not have enough evidence to draw clear conclusions on the role of PRP as an augmentation procedure: among RCT and comparative papers, 16 reported favourable results, 18 obtained no significant difference with or without PRP and 6 underlined the doubtful role of PRP.

With regards to materials type, PRP might not be indicated for b-TCP implants, controversial results are obtained with autologous bone, whereas a better potential seems to lie in the augmentation of HA implants.

However, several aspects have to be clarified, such as what biomaterials can benefit the most from PRP and what is the best protocol for PRP both for production and application. Randomized controlled trials are needed to support the potential of this treatment approach and the advantages and disadvantages of PRP as an augmentation procedure to favour implant integration.

\footnotetext{
Abbreviations

RCT: Randomized controlled trials; FDBA: Freeze-dried bone allograft; BPBM: Bovine porous bone mineral; $\beta$-TCP: $\beta$-tricalcium phosphate; HA: Hydroxyapatite; Ti: Titanium; MGCSH: Medical-grade calcium sulphate hemihydrate; BG: Bioactive glass; GFs: Growth factors; PRP: Platelet-rich plasma; PCBM: Particulate cancellous bone and marrow; GTR: Guided tissue regeneration; PRGF: Plasma rich in growth factors.
}

\section{Competing interests}

The authors declare that they have no competing interests.

\section{Authors' contributions}

Dr. AR: literature analysis, manuscript writing. Dr. GF: literature analysis, manuscript writing. Dr. EK: supervisor and editing. Prof. MM: supervisor, senior consultant, editing. All authors read and approved the final manuscript.

\section{Acknowledgements}

This work was supported by RICERCA FINALIZZATA 2009, Ministero della Salute. Authors also thank Keith Smith for his contribution.

\section{Author details}

${ }^{1}$ Nano-Biotechnology Laboratory, Rizzoli Orthopaedic Institute, Via di Barbiano n 1/10, Bologna 40136, Italy. ${ }^{2}$ Biomechanics Laboratory, Rizzoli Orthopaedic Institute, Via di Barbiano n 1/10, Bologna 40136, Italy.

Received: 25 February 2013 Accepted: 4 November 2013

Published: 21 November 2013

\section{References}

1. Mavrogenis AF, Dimitriou R, Parvizi J, Babis GC: Biology of implant osseointegration. J Muscoloskelet Neuronal Interact 2009, 9(2):61-71.

2. Albrektsson T, Johansson C: Osteoinduction, osteoconduction and osseointegration. Eur Spin J 2001, 10(Suppl 2):S96-101.

3. Gazdag AR, Lane JM, Glaser D, Forster RA: Alternatives to autogenous bone graft efficacy and indications. J Am Acad Orthop Surg 1995, 3(1):1-8.

4. Lieberman JR, Daluiski A, Einhorn TA: The role of growth factors in the repair of bone. Biology and clinical applications. J Bone Joint Surg Am 2002, 84-A(6):1032-1044.

5. Liu Y, de Groot K, Hunziker EB: BMP-2 liberated from biomimetic implant coatings induces and sustains direct ossification in an ectopic rat model. Bone 2005, 36(5):745-757.

6. Wang W, Ouyang Y, Poh CK: Orthopaedic implant technology: biomaterials from past to future. Ann Acad Med Singapore 2011, 40(5):237-244.

7. Kon E, Filardo G, Di Martino A, Marcacci M: Platelet-rich plasma (PRP) to treat sports injuries: evidence to support its use. Knee Surg Sports Traumatol Arthrosc 2011, 19(4):516-527.

8. Alsousou J, Thompson M, Hulley P, Noble A, Willett K: The biology of platelet-rich plasma and its application in trauma and orthopaedic surgery: a review of the literature. J Bone Joint Surg 2009, 91(8):987-996.

9. Tschon M, Fini M, Giardino R, Filardo G, Dallari D, Torricelli P, Martini L, Giavaresi G, Kon E, Maltarello MC, Nicolini A, Carpi A: Lights and shadows concerning platelet products for musculoskeletal regeneration. Front Biosci 2011, 3:96-107.

10. Cole BJ, Seroyer ST, Filardo G, Bajaj S, Fortier LA: Platelet-rich plasma: where are we now and where are we going? Sports Health 2010, 2(3):203-210.

11. Marx RE, Carlson ER, Eichstaedt RM, Schimmele SR, Strauss JE, Georgeff KR Platelet-rich plasma: growth factor enhancement for bone grafts. Oral Surg Oral Med Oral Pathol Oral Radiol Endod 1998, 85(6):638-646.

12. Khairy NM, Shendy EE, Askar NA, El-Rouby DH: Effect of platelet rich plasma on bone regeneration in maxillary sinus augmentation (randomized clinical trial). Int J Oral Maxillofac Surg 2012. In press.

13. Camargo PM, Lekovic V, Weinlaender M, Vasilic N, Madzarevic M, Kenney EB: A reentry study on the use of bovine porous bone mineral, GTR, and platelet-rich plasma in the regenerative treatment of intrabony defects in humans. Int J Periodontics Restorative Dent 2005, 25(1):49-59.

14. Kon E, Filardo G, Delcogliano M, Fini M, Salamanna F, Giavaresi G, Martin I, Marcacci M: Platelet autologous growth factors decrease the osteochondral regeneration capability of a collagen-hydroxyapatite scaffold in a sheep model. BMC Musculoskelet Disord 2010, 11:220.

15. Hanna R, Trejo PM, Weltman RL: Treatment of intrabony defects with bovine-derived xenograft alone and in combination with platelet-rich plasma: a randomized clinical trial. J Periodontol 2004, 75(12):1668-1677.

16. Czuryszkiewicz-Cyrana J: Comparison of regeneration efficacy of parodontium tissue after application of autogenous bone with platelet rich plasma and biomaterials cerasorb with platelet rich plasma. Ann Acad Med Stetin 2008, 54(2):86-92. Polish.

17. Lekovic V, Camargo PM, Weinlaender M, Vasilic N, Aleksic Z, Kenney EB: Effectiveness of a combination of platelet-rich plasma, bovine porous bone mineral and guided tissue regeneration in the treatment of mandibular grade II molar furcations in humans. J Clin Periodontol 2003, 30(8):746-751

18. Luaces-Rey R, Arenaz-Búa J, Lopez-Cedrún-Cembranos JL, Herrero-Patiño S, Sironvalle-Soliva S, Iglesias-Candal E, Pombo-Castro M: Is PRP useful in alveolar cleft reconstruction? Platelet-rich plasma in secondary alveoloplasty. Med Oral Patol Oral Cir Bucal 2010, 15(4):e619-623. 
19. Camargo PM, Lekovic V, Weinlaender M, Vasilic N, Madzarevic M, Kenney EB: Platelet-rich plasma and bovine porous bone mineral combined with guided tissue regeneration in the treatment of intrabony defects in humans. J Periodontal Res 2002, 37(4):300-306.

20. Badr M, Coulthard P, Alissa R, Oliver R: The efficacy of platelet-rich plasma in grafted maxillae. A randomised clinical trial. Eur J Oral Implantol 2010, 3(3):233-244.

21. Ozdemir B, Okte E: Treatment of intrabony defects with betatricalciumphosphate alone and in combination with platelet-rich plasma. J Biomed Mater Res B Appl Biomater 2012, 100(4):976-983.

22. Bettega G, Brun JP, Boutonnat J, Cracowski JL, Quesada JL, Hegelhofer $H$, Drillat $\mathrm{P}$, Richard MJ: Autologous platelet concentrates for bone graft enhancement in sinus lift procedure. Transfusion 2009, 49(4):779-785.

23. Saini N, Sikri P, Gupta H: Evaluation of the relative efficacy of autologous platelet-rich plasma in combination with $\beta$-tricalcium phosphate alloplast versus an alloplast alone in the treatment of human periodontal infrabony defects: a clinical and radiological study. Indian J Dent Res 2011, 22(1):107-115

24. Lee C, Nishihara K, Okawachi T, Iwashita Y, Majima HJ, Nakamura N: A quantitative radiological assessment of outcomes of autogenous bone graft combined with platelet-rich plasma in the alveolar cleft. Int J Oral Maxillofac Surg 2009, 38(2):117-125.

25. Harnack L, Boedeker RH, Kurtulus I, Boehm S, Gonzales J, Meyle J: Use of platelet-rich plasma in periodontal surgery-a prospective randomised double blind clinical trial. Clin Oral Investig 2009, 13(2):179-187.

26. Schaaf $H$, Streckbein $P$, Lendeckel $S$, Heidinger KS, Rehmann $P$, Boedeker RH, Howaldt HP: Sinus lift augmentation using autogenous bone grafts and platelet-rich plasma: radiographic results. Oral Surg Oral Med Oral Pathol Oral Radiol Endod 2008, 106(5):673-678.

27. Döri F, Huszár T, Nikolidakis D, Tihanyi D, Horváth A, Arweiler NB, Gera I, Sculean A: Effect of platelet-rich plasma on the healing of intrabony defects treated with Beta tricalcium phosphate and expanded polytetrafluoroethylene membranes. J Periodonto/ 2008, 79(4):660-669.

28. Consolo U, Bertoldi C, Zaffe D: Intermittent loading improves results in mandibular alveolar distraction osteogenesis. Clin Oral Implants Res 2006, 17(2):179-187.

29. Yassibag-Berkman Z, Tuncer O, Subasioglu T, Kantarci A: Combined use of platelet-rich plasma and bone grafting with or without guided tissue regeneration in the treatment of anterior interproximal defects. J Periodontol 2007, 78(5):801-809.

30. Raghoebar GM, Schortinghuis J, Liem RS, Ruben JL, van der Wal JE, Vissink A: Does platelet-rich plasma promote remodeling of autologous bone grafts used for augmentation of the maxillary sinus floor? Clin Oral Implants Res 2005, 16(3):349-356.

31. Wiltfang J, Schlegel KA, Schultze-Mosgau S, Nkenke E, Zimmermann R, Kessler P: Sinus floor augmentation with beta-tricalciumphosphate (beta-TCP): does platelet-rich plasma promote its osseous integration and degradation? Clin Oral Implants Res 2003, 14(2):213-218.

32. Markou N, Pepelassi E, Vavouraki H, Stamatakis HC, Nikolopoulos G, Vrotsos I, Tsiklakis K: Treatment of periodontal endosseous defects with platelet-rich plasma alone or in combination with demineralized freeze-dried bone allograft: a comparative clinical trial. J Periodonto/ 2009, 80(12):1911-1919.

33. Menezes LM, Rao J: Long-term clinical evaluation of platelet-rich plasma in the treatment of human periodontal intraosseous defects: a comparative clinical trial. Quintessence Int 2012, 43(7):571-582.

34. Piemontese M, Aspriello SD, Rubini C, Ferrante L, Procaccini M: Treatment of periodontal intrabony defects with demineralized freeze-dried bone allograft in combination with platelet-rich plasma: a comparative clinical trial. J Periodontol 2008, 79(5):802-810.

35. Vaishnavi C, Mohan B, Narayanan LL: Treatment of endodontically induced periapical lesions using hydroxyapatite, platelet-rich plasma, and a combination of both: An in vivo study. J Conserv Dent 2011, 14(2):140-146.

36. Kassolis JD, Reynolds MA: Evaluation of the adjunctive benefits of platelet-rich plasma in subantral sinus augmentation. J Craniofac Surg 2005, 16(2):280-287.

37. Okuda K, Tai H, Tanabe K, Suzuki H, Sato T, Kawase T, Saito Y, Wolff LF, Yoshiex H: Platelet-rich plasma combined with a porous hydroxyapatite graft for the treatment of intrabony periodontal defects in humans: a comparative controlled clinical study. J Periodontol 2005, 76(6):890-898.
38. Anitua $E$, Prado R, Orive G: Bilateral sinus elevation evaluating plasma rich in growth factors technology: a report of five cases. Clin Implant Dent Relat Res 2012, 14(1):51-60

39. Demir B, Sengün $D$, Berberoğlu A: Clinical evaluation of platelet-rich plasma and bioactive glass in the treatment of intra-bony defects. J Clin Periodontol 2007, 34(8):709-715.

40. Cabbar F, Güler N, Kürkcü M, Işeri U, Sençift K: The effect of bovine bone graft with or without platelet-rich plasma on maxillary sinus floor augmentation. J Oral Maxillofac Surg 2011, 69(10):2537-2547.

41. Kaushick BT, Jayakumar ND, Padmalatha O, Varghese S: Treatment of human periodontal infrabony defects with hydroxyapatite $+\beta$ tricalcium phosphate bone graft alone and in combination with platelet rich plasma: a randomized clinical trial. Indian J Dent Res 2011, 22(4):505-510.

42. Yilmaz S, Kabadayi C, Ipci SD, Cakar G, Kuru B: Treatment of intrabony periodontal defects with platelet-rich plasma versus platelet-poor plasma combined with a bovine-derived xenograft: a controlled clinical trial. J Periodontol 2011, 82(6):837-844.

43. Smrke D, Gubina B, Domanoviç D, Rozman P: Allogeneic platelet gel with autologous cancellous bone graft for the treatment of a large bone defect. Eur Surg Res 2007, 39(3):170-174

44. Camargo PM, Lekovic V, Weinlaender M, Divnic-Resnik T, Pavlovic M, Kenney EB: A surgical reentry study on the influence of platelet-rich plasma in enhancing the regenerative effects of bovine porous bone mineral and guided tissue regeneration in the treatment of intrabony defects in humans. J Periodontol 2009, 80(6):915-923.

45. Wei LC, Lei GH, Sheng PY, Gao SG, Xu M, Jiang W, Song Y, Luo W: Efficacy of platelet-rich plasma combined with allograft bone in the management of displaced intra-articular calcaneal fractures: a prospective cohort study. J Orthop Res 2012, 30(10):1570-1576.

46. Torres J, Tamimi F, Martinez PP, Alkhraisat MH, Linares R, Hernández G, TorresMacho J, López-Cabarcos E: Effect of platelet-rich plasma on sinus lifting: a randomized-controlled clinical trial. J Clin Periodontol 2009, 36(8):677-687.

47. Amini AR, Wallace JS, Nukavarapu SP: Short-term and long-term effects of orthopedic biodegradable implants. J Long Term Eff Med Implants 2011, 21(2):93-122.

48. Döri F, Huszár T, Nikolidakis D, Arweiler NB, Gera I, Sculean A: Effect of platelet-rich plasma on the healing of intrabony defects treated with an anorganic bovine bone mineral and expanded polytetrafluoroethylene membranes. J Periodontol 2007, 78(6):983-990.

49. Sys J, Weyler J, Van Der Zijden T, Parizel P, Michielsen J: Platelet-rich plasma in mono-segmental posterior lumbar interbody fusion. Eur Spine J 2011, 20(10):1650-1657.

50. Döri F, Huszár T, Nikolidakis D, Arweiler NB, Gera I, Sculean A: Effect of platelet-rich plasma on the healing of intra-bony defects treated with a natural bone mineral and a collagen membrane. J Clin Periodontol 2007, 34(3):254-261

51. Dallari D, Savarino L, Stagni C, Cenni E, Cenacchi A, Fornasari PM, Albisinn U, Rimondi E, Baldini N, Giunti A: Enhanced tibial osteotomy healing with use of bone grafts supplemented with platelet gel or platelet gel and bone marrow stromal cells. J Bone Joint Surg Am 2007, 89(11):2413-2420.

52. Monov G, Fuerst G, Tepper G, Watzak G, Zechner W, Watzek G: The effect of platelet-rich plasma upon implant stability measured by resonance frequency analysis in the lower anterior mandibles. Clin Oral Implants Res 2005, 16(4):461-465.

53. Poeschl PW, Ziya-Ghazvini F, Schicho K, Buchta C, Moser D, Seemann R, Ewers R, Schopper C: Application of platelet-rich plasma for enhanced bone regeneration in grafted sinus. J Oral Maxillofac Surg 2012, 70(3):657-664

54. Inchingolo F, Tatullo M, Marrelli M, Inchingolo AM, Inchingolo AD, Dipalma G, Flace P, Girolamo F, Tarullo A, Laino L, Sabatini R, Abbinante A, Cagiano R: Regenerative surgery performed with platelet-rich plasma used in sinus lift elevation before dental implant surgery: an useful aid in healing and regeneration of bone tissue. Eur Rev Med Pharmacol Sci 2012, 16(9):1222-1226.

55. Esposito M, Grusovin MG, Coulthard P, Worthington HV: The efficacy of various bone augmentation procedures for dental implants: a Cochrane systematic review of randomized controlled clinical trials. Int J Oral Maxillofac Implants 2006, 21(5):696-710.

56. Wetzel AC, Stich H, Caffesse RG: Bone apposition onto oral implants in the sinus area filled with different grafting materials. A histological study in beagle dogs. Clin Oral Implants Res 1995, 6(3):155-163.

57. Dormont D: How to limit the spread of Creutzfeldt-Jakob disease. Infect Control Hosp Epidemiol 1996, 17(8):521-528. 
58. Calori GM, Mazza E, Colombo M, Ripamonti C: The use of bone-graft substitutes in large bone defects: any specific needs? Injury 2011, 42(2):S56-63.

59. Anderegg CR, Alexander DC, Freidman M: A bioactive glass particulate in the treatment of molar furcation invasions. J Periodontol 1999, 70(4):384-387.

60. Schepers EJ, Ducheyne P: Bioactive glass particles of narrow size range for the treatment of oral bone defects: a 1-24 month experiment with several materials and particle sizes and size ranges. J Oral Rehabil 1997, 24(3):171-181.

61. Lovelace TB, Mellonig JT, Meffert RM, Jones AA, Nummikoski PV, Cochran $\mathrm{DL}$ : Clinical evaluation of bioactive glass in the treatment of periodontal osseous defects in humans. J Periodontol 1998, 69(9):1027-1035.

62. Kutkut A, Andreana S, Kim HL, Monaco E Jr: Extraction socket preservation graft before implant placement with calcium sulfate hemihydrate and platelet-rich plasma: a clinical and histomorphometric study in humans. J Periodontol 2012, 83(4):401-409.

63. Torres J, Tamimi F, Alkhraisat MH, Manchón A, Linares R, Prados-Frutos JC, Hernández G, López Cabarcos E: Platelet-rich plasma may prevent titanium-mesh exposure in alveolar ridge augmentation with anorganic bovine bone. J Clin Periodontol 2010, 37(10):943-951.

64. Dohan Ehrenfest DM, Rasmusson L, Albrektsson T: Classification of platelet concentrates: from pure platelet-rich plasma (P-PRP) to leucocyte- and platelet-rich fibrin (L-PRF). Trends Biotechnol 2009, 27(3):158-167.

65. Weibrich G, Hansen T, Kleis W, Buch R, Hitzler WE: Effect of platelet concentration in platelet-rich plasma on peri-implant bone regeneration. Bone 2004, 34(4):665-671.

66. Carulli C, Matassi F, Civinini R, Innocenti M: Tissue engineering applications in the management of bone loss. Clin Cases Miner Bone Metab 2013, 10(1):22-25.

67. Yoshida K, Sumita Y, Marukawa E, Harashima M, Asahina I: Effect of platelet-rich plasma on bone engineering with an alloplastic substitute containing BMP2. Biomed Mater Eng 2013, 23(3):163-172.

doi:10.1186/1471-2474-14-330

Cite this article as: Roffi et al:: Does PRP enhance bone integration with grafts, graft substitutes, or implants? A systematic review. BMC

Musculoskeletal Disorders 2013 14:330.

\section{Submit your next manuscript to BioMed Central and take full advantage of:}

- Convenient online submission

- Thorough peer review

- No space constraints or color figure charges

- Immediate publication on acceptance

- Inclusion in PubMed, CAS, Scopus and Google Scholar

- Research which is freely available for redistribution 